Original article

\title{
In vivo laboratory practicals in research-led teaching: An example using glucose tolerance tests in lean and obese mice
}

\author{
Aileen J.F. King ${ }^{\text {a,*}}{ }^{\text {, James E. Bowe }}{ }^{\text {a }}$, Juliet A. Sprake ${ }^{b}$, Ian M. Kinchin ${ }^{c}$ \\ a Diabetes Research Group, King's College London, United Kingdom \\ b Design Department, Goldsmiths, University of London, United Kingdom \\ c King's Learning Institute, King's College London, United Kingdom
}

\section{A R T I C L E I N F O}

\section{Article history:}

Received 12 January 2011

Accepted 19 July 2011

Available online $\mathrm{xxxx}$

\section{Keywords:}

in vivo skills

glucose tolerance test

research-led teaching

\begin{abstract}
A B S T R A C T
The use of animal models is an essential part of medical research and drug development. The essential skills required to be able to do such research includes experimental design, statistical analysis and the actual handling and treating of the animals (in vivo skills). The number of students in the U.K. receiving training in handling and experimenting on animals has declined rapidly in the last few decades which has led to initiatives to increase numbers of students with these skills to meet demand. Within the Department of Pharmacology and Therapeutics at King's College London, we run a course for 2nd year undergraduates entitled "Animal models of disease and injury". This course not only covers the theoretical and ethical aspects of using animals in research, but also contains practical laboratory classes in which students get hands-on experience using animals. One of the laboratory classes we run is a glucose tolerance test in obese and lean mice. This is an example of research-led teaching which aims to develop research skills through engaging students in research like activities. In this paper, we outline the methodology of the glucose tolerance practical and highlight some of the skills we and the students think they gain by research-led teaching such as this.
\end{abstract}

(c) 2011 Elsevier Inc. All rights reserved.

\section{Introduction}

For many years, the use of animals has been a central part of medical research and drug development. The essential skills required to be able to do such research includes experimental design, statistical analysis and the actual handling and treating of the animals (in vivo skills). The number of students receiving training in handling and experimenting on animals has declined rapidly in the last few decades (Report by APBI \& Biosciences Federation, 2005). Indeed twenty years ago, all major pharmacology and physiology courses in the UK contained an in vivo component, whereas now it has been estimated that of 8000 students graduating in these and related subjects every year, only around 200 have any exposure to in vivo skills (Report by APBI \& Biosciences Federation, 2005). Some of the main reasons for the decline in teaching of in vivo skills in universities in the UK include the problems with the logistics in obtaining the relevant licences, financial reasons, decreased number of staff with relevant skills to teach in vivo skills and decreased staff to student ratios (British Pharmacological Society \& the Physiology Society, 2006; Collis, 2006; Report by APBI \& Biosciences Federation, 2005). It has recently been reported that about $75 \%$ of industry, universities, public sector and charity research organizations in the United Kingdom are facing

\footnotetext{
* Corresponding author. Tel.: + 442078486402.

E-mail address: aileen.king@kcl.ac.uk (A.J.F. King).
}

difficulties recruiting graduates with in vivo skills (Report by APBI \& Biosciences Federation, 2005). Therefore if the UK is going to sustain competiveness in attracting global biomedical research, the in vivo skills supply must be addressed (Page, 2008).

It could be argued that industry should not be dictating what we teach our students. However, the four main aims of the higher education funding council in their strategic plan 2006-2011 are as follows (HEFC, 2008):

- Enhancing excellence in learning and teaching.

- Widening participation and fair access.

- Enhancing excellence in research.

- Enhancing the contribution of higher education to the economy and society.

Pharmaceutical companies are threatening to relocate abroad if they can not recruit enough graduates with in vivo skills (Page, 2008), so it is clear that providing in vivo training to students does "enhance the contribution of higher education to the economy and society". In addition, it can be argued that more students trained with in vivo skills will also enhance excellence in research (Page, 2008; Williams, 2005). It is therefore clear that providing this training for undergraduates is not only what future employers want, but is in line with the HEFC strategic plan.

However, many oppose the concept of "employer-designed degrees" and according to Sally Hunt of the University and College 
Union, "Higher education is first and foremost a learning environment, not a training camp for business." (Fearn, 2008). However, in the case of training students in in vivo skills, one important point is that universities themselves are also interested in recruiting graduates and post-graduates with in vivo skills in order to maintain research and teaching in this area (Page, 2008). It can therefore be anticipated that not only employers in the private sector would benefit by increasing the number of students with in vivo skills, but this is also likely to positively impact on the universities themselves. Industry has been accused of being quick to criticize graduates' skills but not doing enough to help (Gill, 2008). However, in response to the shortage of graduates with in vivo skills, the British Pharmacology Society (BPS) Integrative Pharmacology Fund was established and three major pharmaceutical companies in the UK (AstraZeneca, GlaxoSmithKline and Pfizer) committed $£ 4,000,000$ (British Pharmacological Society \& the Physiology Society, 2006). This fund works with the research councils and the Higher Education Funding Committees to increase support for in vivo research and education. However, if one considers the opinion that "higher education is first and foremost a learning environment", then a fundamental question is whether educating students with in vivo skills can have an impact on their learning in general and whether it aids in the quest to teach undergraduate science students to think like scientists (Valter \& Akerlind, 2010).

Within the Department of Pharmacology and Therapeutics at King's College London, we run a course for 2 nd year undergraduates entitled "Animal models of disease and injury". In this paper we address how the in vivo practicals in this and in other courses develop relevant skills in learning to be a scientist. We outline the methodology of the glucose tolerance practical and highlight some of the skills we and the students think they gain by research-led teaching such as this.

\section{Ethics}

We do not suggest that every undergraduate science student should learn in vivo skills, so we target a small number of talented and motivated students who are likely to pursue a career in research.

When using live animals in undergraduate teaching, it is essential that ethics is considered in both the course design and throughout the teaching of the course. In the "Animal models of disease and injury" module, ethics are emphasised throughout the course with particular sessions in the module dedicated to this, including the students writing an ethical review process application as part of their assessment. We also have external speakers from the National Centre for the Replacement, Refinement and Reduction of Animals in Research (NC3Rs) holding a two hour workshop with the students. All the practical sessions are designated mild on the home office licence and all students and sessions are appropriately licenced. In addition we are also careful to highlight ethical issues and the 3Rs during the practical sessions themselves.

\section{Glucose tolerance test practical: methods and materials}

Although the course has a capacity of 24 , each practical has no more than 12 students. Students work in pairs and each pair is given one lean and one obese mouse. All results shown are generated by students in a practical.

\subsection{Animals}

Six obese (leptin deficient ob/ob) and six lean male mice on a C57Bl/6 background were obtained from Harlan, Bichester, UK. All students were licenced and all procedures were carried out under licence, in accordance with the UK Home Office Animals (Scientific Procedures) Act 1986.

\subsection{Procedure}

Mice are fasted $6 \mathrm{~h}$ prior to the experiment and have free access to water throughout the experiment. Students are advised prior to the experiment that noise levels should be kept to a minimum and that stressed mice will have altered blood glucose levels. Mice are weighed and then a small blood sample is obtained by a needle prick (27 gauge) at the end of their tail. Blood glucose is measured using an Accu-Chek (Roche Diagnostics) blood glucose meter and strips. A sample of less than $1 \mu \mathrm{l}$ is required. After the basal blood glucose has been measured, the mice are then injected intraperitoneally with $2 \mathrm{~g} / \mathrm{kg}$ glucose solution (30\%). Blood glucose is then measured 15,30 , 60 and 120 min after the glucose injection.

The mice are then killed by cervical dislocation and the pancreas and one testicular fat pad are dissected out and weighed.

\subsection{Typical results}

As Fig. 1 shows, the obese mice weigh more than the lean mice. In addition, at all time points, the obese mice have higher blood glucose levels (Fig. 2). Whereas the pancreas has a similar weight to lean mice, the obese mice have much heavier testicular fat pads (Fig. 3).

\subsection{Sources of error}

In general this practical has a very good success rate with never more than one mouse out of twelve not responding to the glucose injection, even with a class full of students who have never done an intraperitoneal injection. It consistently leads to significant results when lean and obese mice are compared with regard to body weight, fat pad weight and blood glucose levels. Pancreas dissection is difficult for students and they usually do not succeed in removing the whole organ. However, they tend to be reasonably consistent in removing the splenic portion of the pancreas. We discuss sources of error after the experimental part of the class and the students also do background reading to try and explain some of their results.

\subsection{Feedback}

Students were asked to fill in an anonymous questionnaire rating their experiences of the course. They were also invited to send any further opinions by email. In addition, students who completed the course in 2009 were sent an e-mail to ask them what their career paths are and whether they have used their in vivo skills since completing the course.

\section{Discussion}

In feedback, students consistently rate the in vivo component as the most useful and enjoyable aspect of the course. Therefore it is worth reflecting on what the students perceive they gain from their in vivo experience.

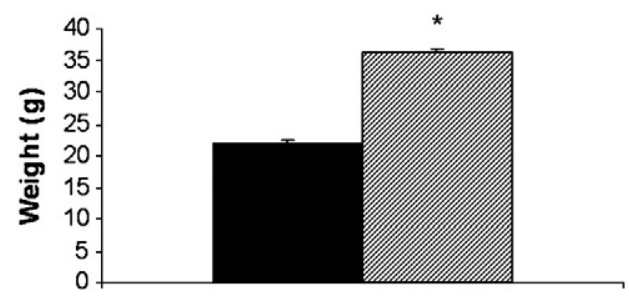

Fig. 1. Weight ( $g$ ) of lean (filled bar) and obese (hatched bar) mice prior to glucose tolerance test. $n=6, p<0.0001$. 


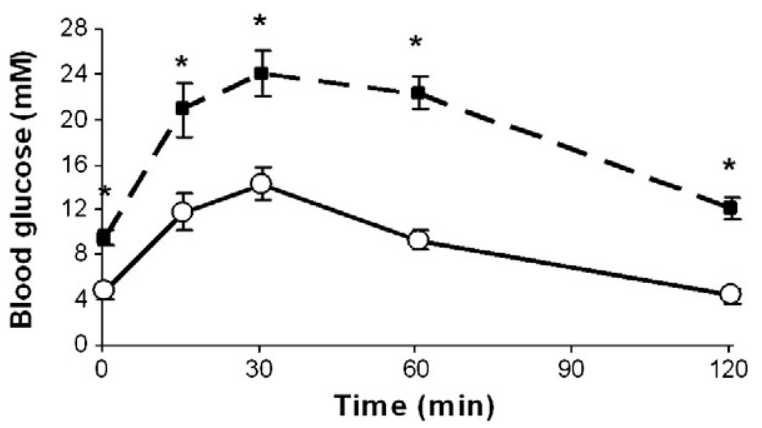

Fig. 2. Glucose tolerance test in lean (black line) and obese (dashed line) after intraperitoneal injection of $2 \mathrm{~g} / \mathrm{kg}$ glucose. Obese mice have significantly higher blood glucose levels ( $p<0.05$ at all time points; 2 way RM ANOVA, $n=6$ ).

\subsection{What do students think they gain from learning in vivo skills?}

Students applying for the module were asked, as part of the application process, why they were interested in studying this course. The majority of students stated that the main reason they wanted to learn these skills was to improve their employment prospects (Applicants for 5BMM0217, 2008; Bonwell \& Eison, 1991). Indeed it is clear that a course such as this will improve handling skills as the students have no prior experience. However, prior to the course, very few students mentioned any direct impact on their learning.

However after the course, student feedback indicated that most students felt that the in vivo practicals complemented the course well and helped them write scientific reports (Table 1). To follow up on this, students were specifically asked to reflect on how they thought the in vivo practicals affected their learning by answering the following question "Has the in vivo component of the course enhanced your learning and if so, in what way?" Some of the responses are shown in Table 2. Some students explained that active learning helped them understand the topic better. For others it is evident that the smaller class size which is required for in vivo practicals helped their learning by having easier access to members of staff. It was also noted by students that doing an experiment themselves helped them to better understand science and experimental design.

\subsection{In vivo practicals as an example of research-led teaching}

In vivo practicals can regarded as research-led teaching which gives some key skills and experiences: handling skills, understanding integrative physiology/pharmacology and data interpretation, which are described in more detail below. The overall aim of this is to provide the skills for students to think like a scientist. Another advantage of

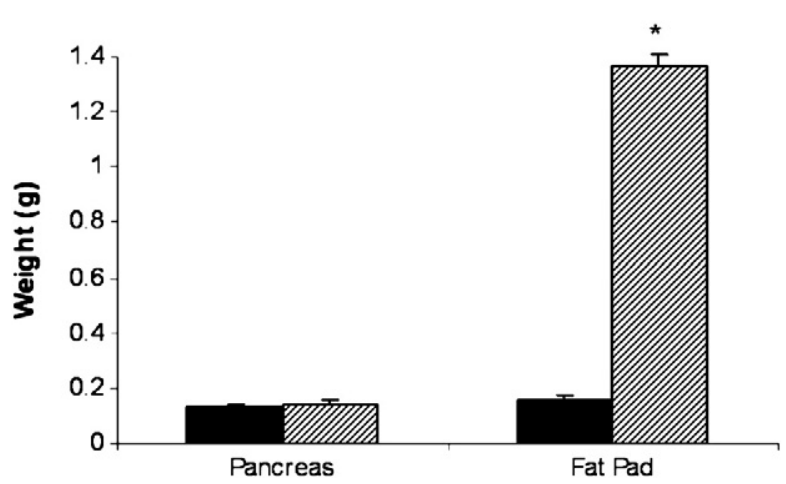

Fig. 3. Weight of pancreas and testicular fat pad in lean (filled bars) and obese (hatched bars) mice. The fat pad was heavier in obese mice $(p<0.0001, t$-test, $n=6)$.
Table 1

Student evaluation on glucose tolerance practical. Values are percentages of students that agreed or fully agreed with the corresponding statements.

\begin{tabular}{|c|c|c|c|c|c|}
\hline & $\begin{array}{l}\text { Fully } \\
\text { agree }\end{array}$ & Agree & Neutral & Disagree & $\begin{array}{l}\text { Completely } \\
\text { disagree }\end{array}$ \\
\hline $\begin{array}{l}\text { The practical complemented } \\
\text { the course well }\end{array}$ & 67 & 33 & 0 & 0 & 0 \\
\hline $\begin{array}{l}\text { The practical enhanced my in } \\
\text { vivo skills }\end{array}$ & 75 & 17 & 8 & 0 & 0 \\
\hline $\begin{array}{l}\text { The practical enhanced my } \\
\text { ability to write a scientific } \\
\text { report. }\end{array}$ & 67 & 25 & 8 & 0 & 0 \\
\hline
\end{tabular}

research led teaching is it can engage students in their own learning (Holbrook, 2005).

\subsection{Handling skills}

This practical is ideal for inexperienced handlers. The obese mice tend to be more docile than the lean mice and therefore are good mice to handle if any of the students are particularly wary. The first step of the protocol involves weighing the mice, which is relatively straight forward.

Obtaining the first basal blood sample is also reasonably easy as the students do not have to restrain the mice to achieve this. This works up to the hardest element of the practical for the students: scruffing the mouse and the intraperitoneal injection. In general, this requires oneon-one tuition, which is achieved by having a couple of demonstrators available to help students with this. As mentioned above the most wary students are encouraged to use an obese mouse as these mice tend to move less during the procedure. All students doing this practical have been able to scruff a mouse and it is evident that they come more confident in handling animals throughout the course.

It could be argued that a course such as ours provides quite limited experience in handling and thus would not convey an advantage for employment as further training would be required. However, even limited handling experience allows the students to assess whether they are confident and have the potential to become competent in in vivo skills. This helps them to make an informed decision on whether they would like to pursue a career in in vivo research. This selfselection process allows employers to be confident that the potential employee has the ability and desire to do in vivo work. This in itself is desirable to the employer, who otherwise runs the risk that a new employee who agrees to do in vivo work but has not experienced it finds that they are unable to carry out in vivo work after they have commenced employment. Indeed students themselves claimed that in subsequent job interviews, future employers were showing considerable interest in the fact they had previous experience of in vivo skills.

\subsection{Understanding integrative physiology/pharmacology}

Many students know that obesity can increase your chances of developing diabetes (Hirani, Zaninotto, \& Primatesta, 2007). However, in this practical they can clearly see to what extent blood glucose levels are increased in obese mice. Using these leptin deficient mice the physiology of appetite regulation can also be discussed and the effect of a lack of leptin is clearly seen in the obesity of the mice. The extent of obesity can be visualized during the dissection, with many students surprised about the size of the fat pads. These mice also tend to have fatty livers, which can be seen by the pale color of the liver of the obese mice compared with the livers of the lean mice. The students also note that the obese mice are not as active as the lean mice. Although the practical is based around the effects of obesity on glucose tolerance, students get an overall view of the effect of obesity on the whole animal. 
Table 2

A selection of student answers to the question "Has the in vivo component of the course enhanced your learning and if so, in what way?".

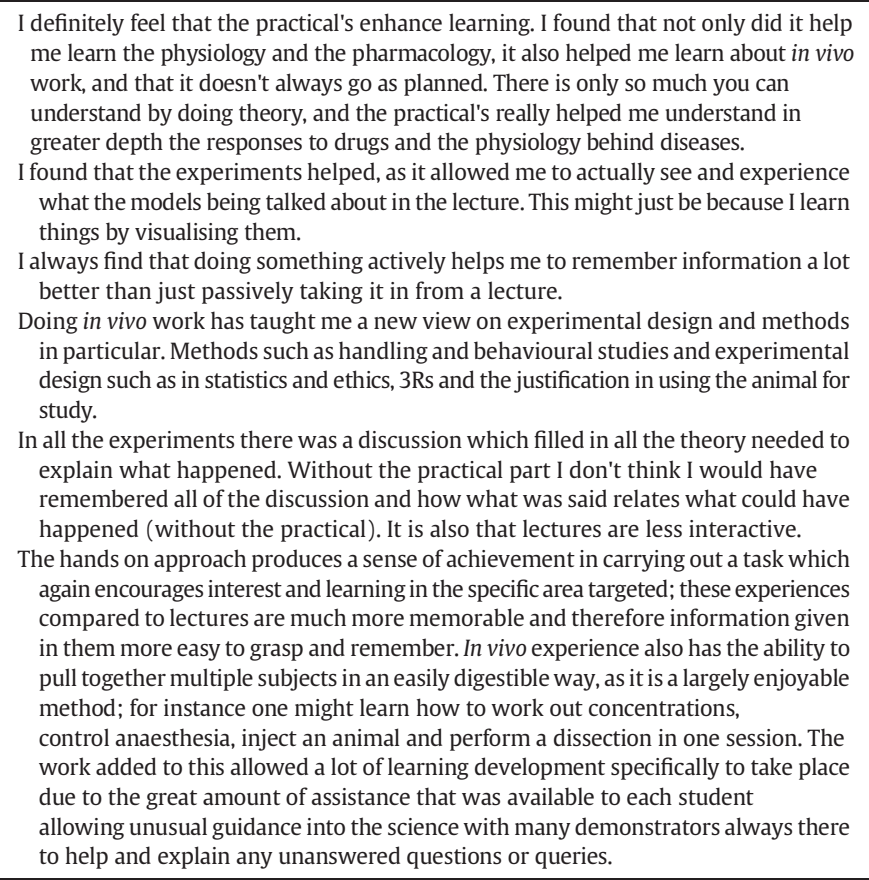

\subsection{Data interpretation}

Many students have noted that statistics is much more fun when you have yourself generated the data. In writing up the report in the format of a scientific paper, the students are able to apply statistics to their data. From this they should draw sound conclusions. However, some students seem reluctant to accept that there could be a situation where there are no differences between the groups. In the glucose tolerance practical this occurs with the weight of the pancreas. Some students have read that pancreatic islet size is increased in the ob/ob mice but have failed to remember that islets comprise only $1 \%$ of the total pancreas volume. Therefore it is unlikely you could detect such a difference merely from weighing the pancreas. However, they are desperate to show that their data could fit in with this perceived idea that the pancreases in the obese mouse should weigh more. This leads to elaborate discussions about why they did not achieve significant differences. However, not only can preconceived ideas affect the students' interpretation, but if they do not use statistics, put in error bars and use appropriate scales on a graph, then also the manner in which the students plot the data can mislead them. One student generated a graph in excel without error bars (shown in the left panel of Fig. 4). Without doing appropriate statistics, the student concluded that the pancreases of the obese mice weighed more, failing to notice it was a few milligrams on a scale of around $140 \mathrm{mg}$. A more appropriate plot can be seen in the right panel of Fig. 4 , where it is clear that there are no significant differences between the groups.

Although in science it is common that we have to deal with "no significant differences between the groups", many student practicals are specifically designed to show differences. It is therefore of value to add a component such as weighing the pancreas to emphasize to students that in science not every experiment leads to statistically significant results and this can either be due to large variation, technical issues or quite simply because the groups really are not different.

\subsection{Learning to be a scientist}

Learning to be a research scientist should incorporate routine skills and activities that scientists use such as hypothesis, experimental design, experimentation, analysis and scientific deduction (Holbrook, 2005). Prior to starting the practical, students are encouraged to come up with a hypothesis and experimental design is discussed. For example we point out that this particular experiment cannot be done blind as the mice have such obvious differences in phenotype. The students experience the experimentation skills during the practical and analysis and scientific deduction is achieved by them writing up their report.

Another important part of science is that things do not always go as planned. In the vast majority of mice, if you inject glucose, the blood glucose in the mouse will rise, peaking at around $30 \mathrm{~min}$ after injection, as demonstrated in Fig. 2. However, in several instances the results may differ from this. This can be due to biological variation or technical issues (the injection was not in the peritoneal cavity (Miner, Koehler, \& Greenaway, 1969)). This kind of information is usually not conveyed to students in the lecture theatre as in general it is important that students get the main point "when you inject glucose, the blood glucose rises", rather than complicate the issues by adding "but now and again that might not happen". However, part of being a scientist and planning experiments is understanding that you have to take into account results that deviate from normal. This understanding requires that students are able to link their experiential learning (practical knowledge) with their conceptual learning (theoretical knowledge) and appreciate how the two articulate (Kinchin, 2010; Valter \& Akerlind, 2010). Research-led teaching such as the glucose tolerance practical is particularly important in helping students gain necessary skills in thinking like a scientist, by simulating scientific thinking (Holbrook, 2005).

\subsection{Students engagement in their own learning}

Research-led teaching often engages students and encourages deeper learning approaches as it is often more relevant to student career aspirations, typically more interesting and likely to be more intellectually challenging (Holbrook, 2005).

In one practical, a student asked how much the liver weighed, which was not originally a part of the practical. The student was encouraged to
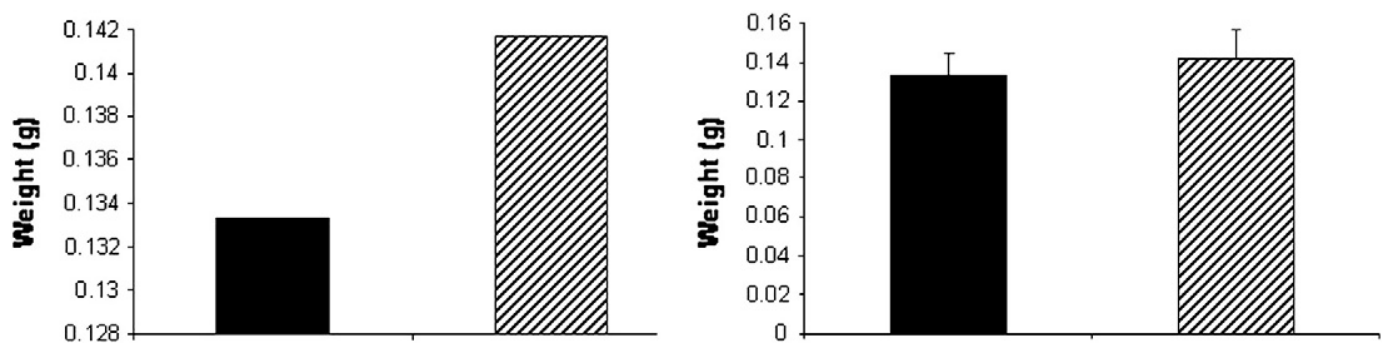

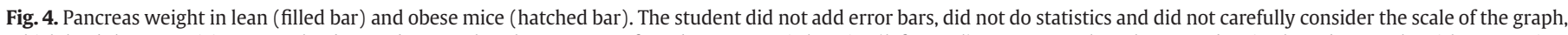

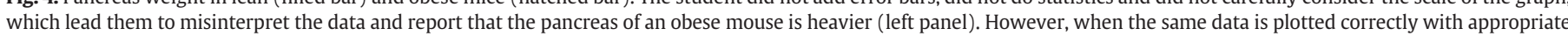
statistical analysis, it is clear that there are no differences between the groups (right panel). $(t$-test $p=0.66, n=6)$. 
follow their curiosity and weigh the liver of the obese and lean mice, which prompted other students to do likewise. This resulted in a new set of data, generated by the students' engagement in their own learning. The students also become very engaged in whether the injection worked or not, which they find out 15 min after the injection when the blood glucose levels should have risen. If they have indeed risen, the students show enthusiasm about their successful injection and a subsequent increased interest in the blood glucose levels. In the very few cases that the blood glucose level does not rise at all, it is usually a technical reason, most likely injection into the wrong site. In these cases the student can concentrate on the fact that they did achieve the difficult part, by picking up and immobilizing the mouse to enable the injection. However their own self-assessment of the fact that the injection did not make the blood glucose level rise can add to their understanding as they consider biological and technical reasons for this. By measuring the blood glucose levels themselves, the students feel more in control, as they themselves are the first to know whether their injection worked and can report this to the instructor rather than vice versa. It has been suggested that active learning such as this has a powerful impact on students learning (Bonwell \& Eison, 1991).

\subsection{Career choice of students}

We have contacted students who studied the course in 2008-2009 to find how useful the course had been to them in terms of their career. Out of the 12 students we successfully made contact with 8 . Of these 8 students, 5 did an extramural year in industry. Two are currently doing a $\mathrm{PhD}$, two have currently got a $\mathrm{PhD}$ position lined up and three are currently looking for a PhD position. One student is currently studying at Masters level. Six students have used in vivo skills in an extramural year or have an in vivo-based $\mathrm{PhD}$. Seven of eight spontaneously wrote that they believed that the course has helped them to secure an extramural placement or a $\mathrm{PhD}$ position. It is therefore clear that most of the students targeted for this course did pursue a career in science, several of whom went on to use their in vivo skills subsequently and thus were ideal candidates for an in vivo based course such as this.
In conclusion, although it could be seen as unethical to provide such training for all science students, it is highly desirable that students planning a career in medical research or drug development have the opportunity to learn in vivo skills. Research-led teaching such as this not only supplies them with highly sought after handling skills but helps to engage students in the subject. Indeed this provides an opportunity for science students to engage in real science and learn how to think like a scientist.

\section{Reference}

Applicants for 5BMM0217. (2008). Application form for 5BBM0217: Animal models of disease and injury. Personal Communication.

Bonwell, C. C., \& Eison, J. A. (1991). 1991. ERIC Digests: Active Learning. Creating excitement in the classroom.

British Pharmacological Society and the Physiology Society (2006). Tackling the need to teach integrative pharmacology and physiology: problems and ways forward. Trends in Pharmacological Sciences, 27, 130-133.

Collis, M. G. (2006). Essay - Integrative pharmacology and drug discovery - is the tide finally turning? Nature Reviews. Drug Discovery, 5, 377-379.

Fearn, H. (2008, November 27). The class of 2020? Times Higher Education.

Gill, J. (2008, August 28). Employers 'stuck in 1970s' over co-funding. Times Higher Education.

HEFC (2008). Strategic plan 2006-2011.

Hirani, V., Zaninotto, P., \& Primatesta, P. (2007). Generalised and abdominal obesity and risk of diabetes, hypertension and hypertension-diabetes co morbidity in England. Public Health Nutrition, 11, 521-527.

Holbrook, N. J. (2005). Simulating scientific thinking online: An example of researchled teaching. Higher Education Research and Development, 24(3), 201-213.

Kinchin, I. M. (2010). Solving Cordelia's dilemma: Threshold concepts within a punctuated model of learning. Journal of Biological Education, 44(2), 53-57.

Miner, N. A., Koehler, J., \& Greenaway, L. (1969). Intraperitoneal injection of mice. Applied Microbiology, 17, 250-251.

Page, C. (2008). In-vivo skills and UK competitiveness in biomedical sciences. Lancet, 371, 708-709.

Report by APBI \& Biosciences Federation (2005). In vivo sciences in the UK: sustaining the supply of skills in the 21st century. (Rep. No. Accessed December 2008).

Valter, K., \& Akerlind, G. (2010). Introducing students to ways of thinking and acting like a researcher: A case study of research-led education in the sciences. International Journal of Teaching and Learning in Higher Education, 22(1), 89-97.

Williams, M. (2005). Systems and integrative biology as alternative guises for pharmacology: Prime time for an iPharm concept? Biochemical Pharmacology, 70, 1707-1716. 